\title{
Maintaining CSF drainage at external ventricular drains may help prevent catheter-related infections
}

\author{
Ali Razmkon - Atefeh Bakhtazad
}

Received: 20 March 2009/Accepted: 20 March 2009/Published online: 18 April 2009

(C) Springer-Verlag 2009

Sir,

We read with interest the comprehensive study by Hoefnagel et al. [1] entitled "Risk factors for infections related to external ventricular drainage". Indeed, among various forms of intracranial pressure (ICP) monitors, ventriculostomy remains unique and the most ideal $[2,3]$. It provides the neurosurgeon the option of therapeutic cerebrospinal fluid (CSF) drainage in addition to routine ICP monitoring [2]. The enthusiasm for the use of external ventricular drains (EVD) has unfortunately been tempered by the increased risk of ventriculomeningitis [2].

Long-standing controversy exists about the risk factors of developing ventriculostomy-related infections. Hemorrhagic CSF, extended duration of ventriculostomy, catheter manipulation and previous craniotomy, as well as many other factors, have been proven to increase the rate of infections [1-5]. We have observed in our ICU patients that those with pure ICP monitors without temporary drainage are infected more frequently and sooner than those for whom CSF drainage is maintained at least temporarily.

A few studies have pointed controversially to the same issue. Smith and Alksne [5] suggested that the use of the ventriculostomy as an EVD rather than an ICP monitor may predispose the patient to CSF infection. However, Schultz et al. [4] and Mayhall et al. [3] found no such association between CSF drainage and an increased risk of infection. Retrospective analysis of our data

\footnotetext{
A. Razmkon $(\bowtie) \cdot$ A. Bakhtazad

Department of Neurosurgery, Shiraz Faculty of Medicine,

Shiraz University of Medical Sciences,

P.O.Box 71455-166, Shiraz, Iran

e-mail: ali.razmkon@gmail.com
}

(unpublished) has revealed a higher rate of infection in pure ICP monitors. Such controversy may be due to the interference of confounding factors, many of which have or have not been found causative in different studies.

In biologic fluid-filled systems associated with the risk of microbial contamination, obstruction to flow has been long known to be associated with stasis and infection. This is evident in the case of urinary tract infections and cholangitis. This condition does not occur in isolated body compartments such as the heart or brain ventricular system. However, when such closed systems are exposed to the threat of ascending bacterial infections in the setting of external diversion of CSF flow (EVDs), then the rules will apply. Maintenance of CSF drainage in EVDs (as opposed to pure ICP monitors) counteracts stasis, which may be effective in preventing ascending ventriculostomy-related infections.

\section{References}

1. Hoefnagel D, Dammers R, Ter Laak-Poort MP, Avezaat CJ (2008) Risk factors for infections related to external ventricular drainage. Acta Neurochir (Wien) 150:209-214. doi:10.1007/s00701-0071458-9

2. Lozier AP, Sciacca RR, Romagnoli MF, Connolly ES (2002) Ventriculostomy-related infections: a critical review of the literature. Neurosurgery 51:170-182. doi:10.1097/00006123-20020 7000-00024

3. Mayhall CG, Archer NH, Lamb VA, Spadora AC, Baggett JW, Ward JD, Narayan RK (1984) Ventriculostomy-related infections: a prospective epidemiologic study. N Engl J Med 310:553-559

4. Schultz M, Moore K, Foote AW (1993) Bacterial ventriculitis and duration of ventriculostomy catheter insertion. J Neurosci Nurs 25:158-164

5. Smith RW, Alksne JF (1976) Infections complicating the use of external ventriculostomy. J Neurosurg 44:567-570 